\title{
Remaining childless or postponing first birth?
}

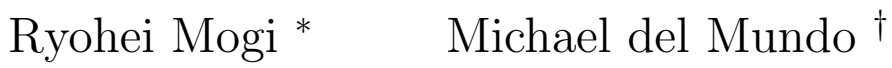

Last revision: November 28, 2018

\begin{abstract}
Childlessness has received attention in the past decades, as it may indicate a new lifestyle and has substantial influences on many aspects of the female life course. An increase in the number of childless people has been observed throughout Europe, North America, and Japan. Accompanying this trend, the mean age at first childbirth has increased. However, whether the phenomenon of remaining childless or that of postponing first childbirth is the main contributor has not been clearly investigated. The aim of this study is to quantify those effects using a decomposition method. We employ the classical life table method to measure changes in first childbirth behavior. Life expectancy is normally used in mortality research to represent the average number of years people live. In childlessness (first childbirth) research, life expectancy signifies the expected number of years without children, as the event of focus is first childbirth. Thus, we define the expected years without children as age 15 to age 50 (EYWC) using the Coale-McNeil model. To avoid the problems of truncation and censoring, only completed cohort fertility data of eight selected countries from the Human Fertility Database are examined. EYWC is decomposed into three factors: remaining childless, postponing first childbirth, and expansion of the standard deviation of mean age at first childbirth. Results of the decomposition show that postponement is mainly occurred in

${ }^{*}$ Centre d’Estudis Demográfics, Universitat Autónoma de Barcelona. Email: rmogi@ced.uab.es.

${ }^{\dagger}$ Division of Social Statistics and Demography, University of Southampton.
\end{abstract}


North America and Northern European countries. Contrarily, remaining childless is observed as the main contributor in Japan and Portugal.

Keywords: Childlessness, decomposition method, postpone first-birth, Coale-McNeil model, life expectancy

\section{Introduction}

The trend of childlessness has steadily increased in recent decades. For example, according to Kreyenfeld and Konietzka (2017), more than $20 \%$ of women in German-speaking countries were childless at the end of their reproductive period. This increasing trend can be observed throughout Europe (Beaujouan et al. 2015; Miettinen et al. 2015; Kreyenfeld and Konietzka 2017), North America (the USA: Frejka (2017), Canada: Ravanera and Beaujot (2014)) and Japan (Raymo et al. 2015). It was also reported that the future proportion of childless couples is projected to increase with the divergence of countries (Sobotka 2017). Becoming a mother or remaining childless influences various aspects of a woman's life. It affects not only aggregate fertility (Zeman et al. 2017) but also income (Budig et al. 2012), health (Kendig et al. 2007), old-age wellbeing (Huijts et al. 2013), and support networks (Albertini and Kohli [20(1). . Therefore, it is worthwhile to have a deep understanding of the trend of childlessness.

Simultaneous with the increase in the number of childless women, the mean age at first childbirth has increased (Beaujouan et al. 2015; Sobotka 2017). This implies that some people tend to remain childless and some tend to postpone their first childbirth. Which phenomenon is the main reason for the change in first birth behaviors? This is an important question because these two phenomena have different determinants and different consequences.

Becoming a mother or staying childless has different consequences and, as a result, influences various aspects of a women's life differently, as we listed above. Moreover, the very 
different life course outcomes of being a mother versus staying childless have implications on social policy construction. The aim of this article is to determine which phenomena is more prevalent: remaining childless or postponing first birth. However, it is not possible to answer this question by only consulting the commonly used macro indices; the proportion of childlessness and the mean age at first birth, even in cohort data, must also be consulted, as both of them have increased.

To quantify the effects of remaining childless and postponement of fertility behaviors, we use a decomposition method presented by Mogi and Canudas-Romo (2018). They measured nuptiality trends by introducing a life years lost into family demography and decomposed it into three factors: nonmarriage, delayed marriage, and expansion of first marriage timing (Mogi and Canudas-Romo 2018). Similar to their research, we illustrate first birth trends using life expectancy and employ this decomposition method to quantify remaining childless and delayed childbirth. The goal of this study is to investigate whether the increase in the average number of years without children is due to the large percentage of the population who remain childless or is just because of first birth timing postponement.

In the following section, we explain our methods: a parametric model for a first birth, the main measure to describe the trend of first childbirth (expected years without children: EYWC) and the decomposition method, as well as the data used. Then, the third section presents the trend of EYWC and the results of its decomposition. In the final section, we mention the discussion, limitations, future developments and conclusion of this study.

\section{Data and methods}

\section{Data}

This study used data from the Human Fertility Database (HFD). The HFD is a joint project of the Max Planck Institute for Demographic Research (MPIDR) in Rostock, Germany and the Vienna Institute of Demography (VID) in Vienna, Austria and is based at MPIDR. Detailed information can be found on its website (http://www.humanfertility.org/cgi-bin/main.php). 
The HFD includes 28 countries, including some in Europe, North and South America, and Asia, and six more countries, for the preliminary release. Specifically, this study used female population counts by age and birth cohort and birth counts by birth order and mother's cohort. Only completed cohort fertility data were used to avoid problems arising from truncation and censoring bias. Based on these criteria, data from eight countries were selected: Canada (1929 - 1962 birth cohort), Czech Republic (1935 - 1965 birth cohort), Japan (1953

- 1965 birth cohort), the Netherlands (1935 - 1963 birth cohort), Norway (1952 - 1965 birth cohort), Portugal (1944 - 1966 birth cohort), Sweden (1955 - 1965 birth cohort), and the USA (1918 - 1965 birth cohort).

\section{Coale-McNeil model for first birth}

The parametric model for overall fertility has been developed well (see, for example, Kostakil and Paraskevi (2007)). In contrast to this trend, there are few models for a first birth. In this study, we use the Coale-McNeil model (CM model) to estimate the age-specific first birth rate. The parameters of the $\mathrm{CM}$ model have conventional demographic meanings and fit best with the aim of our study to quantify the effects of remaining childless and postponement on fertility behaviors.

The CM model was developed to estimate the age patterns of the first marriage of a birth cohort (Coale and Trussell 1.978). Extended from the original use, the CM model has often been applied to the first birth distribution by age as well(Bloom 11982a,b; Bloom and 'Trussell 1.984; Henz and Huinink 1.99.9; Rao 1.987; Trussell and Bloom 1.983). Previous studies applied the CM model to various countries, e.g., Canada, Columbia, Finland, Germany, Italy, and the USA, with much success. The advantage of the CM model is that its parameters have clear demographic meanings as follows. The probability of first birth at age $x$ and time $t$, denoted as $f_{x, t}$, is expressed as:

$$
f_{x, t}=C_{t} \frac{1}{\sigma_{t}} a_{1} \exp \left[a_{2}\left(\frac{x-\mu_{t}}{\sigma_{t}}+a_{3}\right)-\exp \left\{-a_{4}\left(\frac{x-\mu_{t}}{\sigma_{t}}+a_{3}\right)\right\}\right]
$$


where $C_{t}$ pertains to the proportion of the cohort eventually having a child by age 50 at time $t, \mu_{t}$ refers to the mean age at first birth at time $t, \sigma_{t}$ is a measure of the standard deviation of age at first birth at time $t$, and the usual values for the constants are $a_{1}=1.281$, $a_{2}=-1.145, a_{3}=0.805$, and $a_{4}=1.896$. This equation is known as a standardized version of the CM model developed by Rodríguez and Trussell (11980).

Although several models have been used to estimate first birth patterns, these models are not adequately applicable to our study. First, for one feature of the CM model (the convolution structure), an additional term was proposed, which is an exponentially distributed waiting time segment to account for the time from first marriage to first birth. However, Trussell and Bloom ([1983) reported that the original CM model fitted better than the one with the waiting term. Thus, previous research applied the CM model to first birth without using the additional waiting time segment (Bloom 1982a,b; Bloom and 'Trussell 14984; Henz and Huinink 19.99; Rao [प987; Trussell and Bloom 14983). In addition, this is not theoretically appropriate to the current data. As a nonmarital childbirth rate has become common in many developed countries (Eurostat 2018; department of health and human services 2018), the first birth does not always occur after marriage. Thus, the additional term that considers the period after marriage to childbirth is not important to our data studied. The second model is a log-logistic function (LL model). Henz and Huinink ([1999) employed it for the first birth in the German data. However, it does not have a scale parameter, which indicates the proportion of the population that never had children. Hence, it is not applicable to our aim and decomposition method.

Despite the wide use of the CM model to first birth, it has not been statistically examined whether the CM model fits well with the observed age pattern of first birth. The goodnessof-fit using the Kolmogorov-Smirnov tests shows that the CM model estimates the data for all the countries and years well (see Appendix A). For these reasons, we use the CM model to explore the changes in first birth behaviors and the expected years without children (EYWC) over time. 
However, we have to mention the CM model's limitations. There are statistical issues when the CM model is used to estimate the mean and standard deviation of age at first birth (Bloom and Trussell 1984): (1) if the available sample for estimation is restricted to women who have become mothers on or before the survey date, there will be a truncation bias problem; (2) if the data used in estimation are for a sample of all women, there will be a censoring problem if any of the women who will ultimately have a first birth have not done so by the time of the survey (Bloom and Trussell 11984). We avoid those problems using completed cohort fertility data from the HFD.

\section{Expected years without children (EYWC)}

We use life expectancy to measure fertility behaviors. Life expectancy between two ages (e.g., 0 and $X$ ), in classical life table methods, represents the area below a survival function from age 0 to the fixed age $X$. This is interpreted as the average number of years people live between these ages (Preston et al. 2000). In this research analyzing first childbirth, life expectancy is interpreted as the expected years without children, as "death" can be taken as a first birth. The minimum age should be the age of first menstruation and the maximum age is the age of menopause. Thus, we choose the interval ages as ages 15 and 50. Therefore, the EYWC from age 15 to age 50, denoted as ${ }_{35} e_{15}$, is calculated as ${ }_{35} e_{15}(t)=\int_{15}^{50} l_{x, t} d x$. It corresponds to the two lower areas in Fig $\square$ for the 1940 and 1962 birth cohorts. The use of EYWC has two primary advantages. First, as Mogi and Canudas-Romo (2018) noted, this index is used to capture fertility trends in one simple value; thus, it is possible to numerically compare fertility trends at different times and in different countries. Second, it can take into account both the population having children and that without children in one index. While the common indices to show first birth trends are the mean age at first birth and the proportion of childless women, EYWC can illustrate those two indices at the same time. This is very useful in the current world, in which both indices have an increasing trend. 


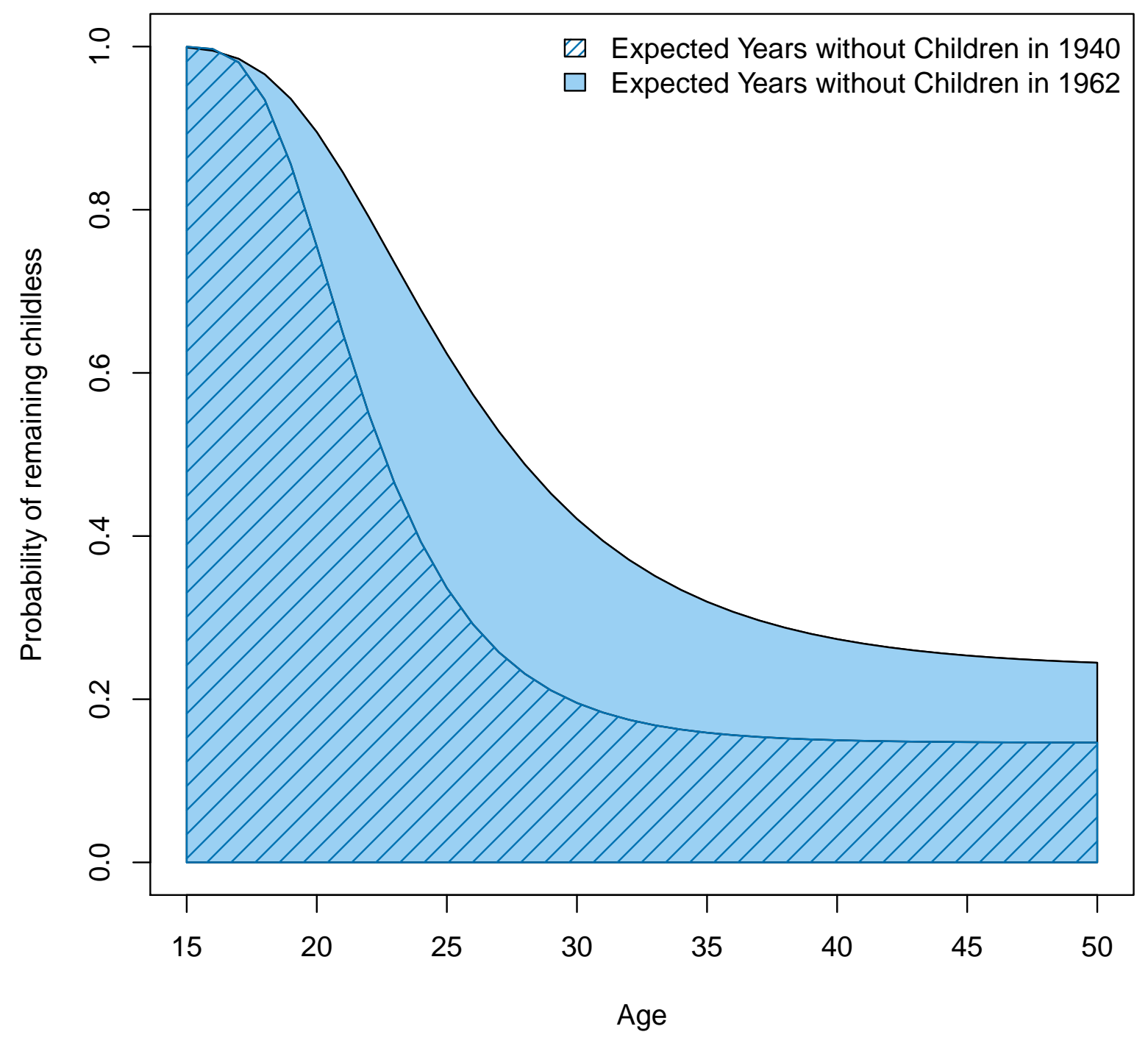

Figure 1: Probability of remaining childless by age among a Canadian female birth cohort in 1940 and 1962

Note: The parameters of the probabilities of remaining childless are $C=0.85, \mu=23.10$, and $\sigma=4.14$ for the 1940 birth cohort and $C=0.76, \mu=26.98$, and $\sigma=6.88$ for the 1962 birth cohort.

Source: Authors' calculations. 


\section{Decomposition method}

We applied the decomposition method developed by Mogi and Canudas-Romo (2018). A detailed explanation can be found in their study (Mogi and Canudas-Romo 2018). The changes in EYWC over time, denoted as ${ }_{35} \dot{e}_{15}(t)$, are decomposed into three parameters: scale (the proportion of the cohort eventually having a child), location (the mean age at first childbirth), and variance (the standard deviation of age at first childbirth). The decomposition of ${ }_{35} \dot{e}_{15}(t)$ can be formulated as

$$
{ }_{35} \dot{e}_{15}(t)=\frac{\partial_{35} e_{15}(t)}{\partial C_{t}} \dot{C}_{t}+\frac{\partial_{35} e_{15}(t)}{\partial \mu_{t}} \dot{\mu}_{t}+\frac{\partial_{35} e_{15}(t)}{\partial \sigma_{t}} \dot{\sigma}_{t},
$$

where each term is the change in ${ }_{35} \dot{e}_{15}(t)$ resulting from changes in the scale, location, and variance. A dot on top of a variable indicates the derivative with respect to time. To interpret the result of decomposition, we should check the degree of each contribution. The largest value shows that the changes in EYWC are mainly caused by that factor, i.e.,

scale factor $\left(\frac{\partial_{35} e_{15}(t)}{\partial C_{t}} \dot{C}_{t}\right)$ : remaining childless, location $\left(\frac{\partial_{35} e_{15}(t)}{\partial \mu_{t}} \dot{\mu}_{t}\right)$ : postponing first birth, or variance $\left(\frac{\partial_{35} e_{15}(t)}{\partial \sigma_{t}} \dot{\sigma}_{t}\right)$ : expansion effect. Whereas our main interest is to quantify the effect of remaining childless and postponing first birth, we take into account the effect of variance as well. The increase in the number of people who have high education and who move internally and internationally makes a community more heterogeneous. This expansion of heterogeneity in the country makes fertility behaviors more varied. Hence, the variance of age at first birth may also increase over time. In addition, it is necessary to consider the variance effect when we use the CM model because it contains the variance parameter $\left(\sigma_{t}\right)$. Appendix $\mathrm{C}$ explains the detailed method of estimating the three parameters of the CM model and applying the decomposition equation to discrete data. 


\section{Results}

Cross-country trend analysis of EYWC

The trends of EYWC for the selected countries are presented in Fig 2 .

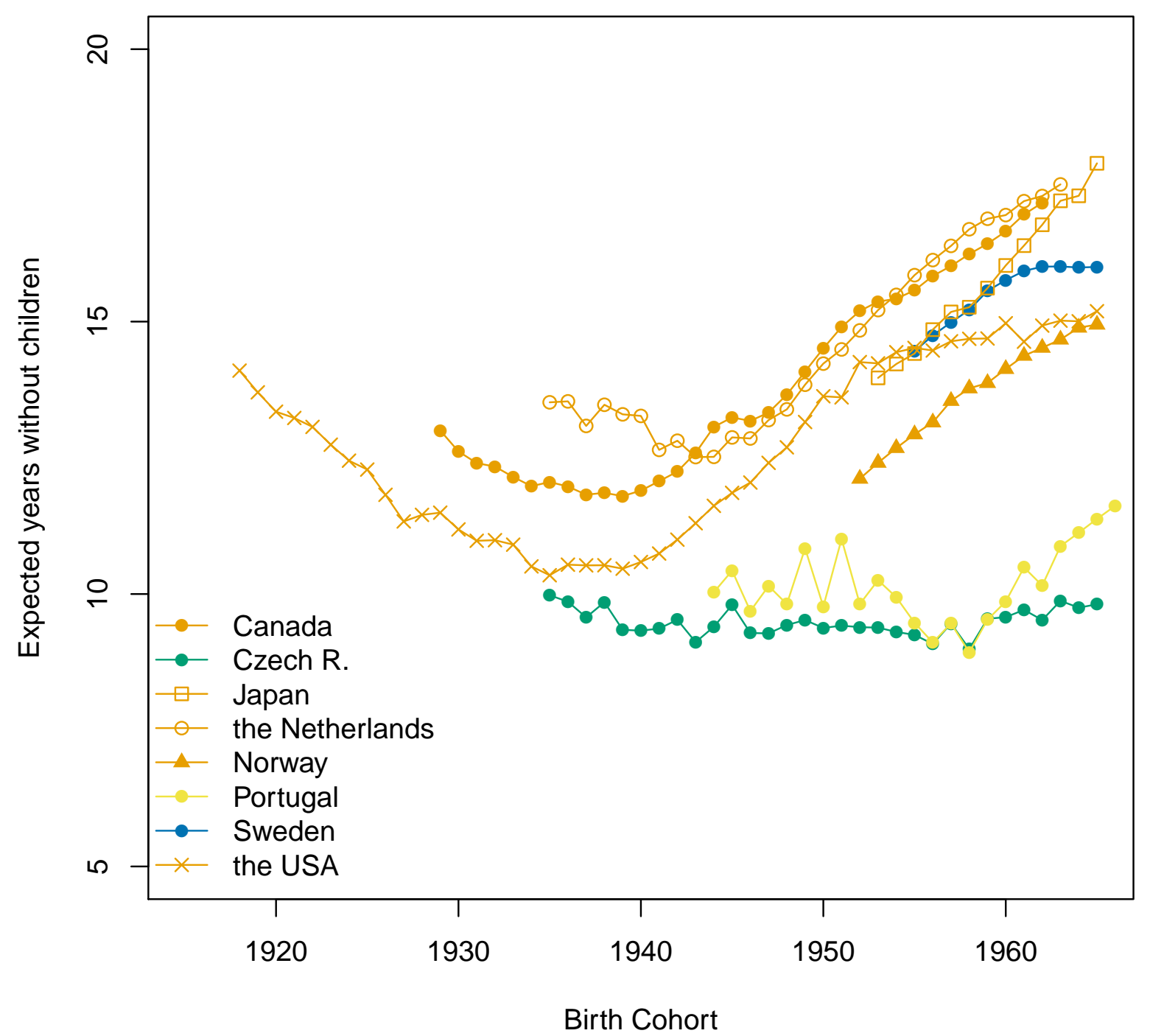

Figure 2: Time trends in expected years without children in eight countries Source: Authors' calculations.

Figure 2 shows that most of the countries in the study had an increasing trend in EYWC starting from the 1940s birth cohorts. The EYWC in Canada declined until the 1940s birth 
cohorts and then started steeply increasing. The 1940 birth cohort in Canada had 12 years of EYWC. This increased to 16.6 years for the 1960 cohort. As EYWC is the expected number of years without children starting from age 15, each number signifies that the expected age at first birth in the specific cohort in a country is $15+$ EYWC. Thus, we can interpret it as the expected age at first birth increased from $27(15+12)$ in the 1940 birth cohort to 31.6 $(15+16.6)$ in the 1960 birth cohort. The USA had a similar increasing trend to Canada until the 1950s birth cohorts. The EYWC in the USA strongly increased from the 1940 birth cohort (10.5 years) to the 1950 birth cohort (13.6 years). This increase, however, slowed after the 1950 birth cohort. The EYWC for the USA only increased by 1.3 years from the 1950 to 1960 birth cohorts. The Netherlands also displayed an increase in EYWC from the 1945 birth cohort. The EYWC for the 1945 birth cohort was 13 years. This figure increased to 17 years for the 1960 birth cohort. The EYWC in other countries, such as Japan and Norway, also showed an increasing trend for all the observable periods. Japan had an EYWC of 14 years for the 1953 birth cohort, which increased to 18 years for the 1965 birth cohort. In the case of Norway, the 1952 cohort had 12 years of EYWC that increased to 15 years by the 1965 cohort.

In contrast to the trends of the countries discussed above, Portugal, Sweden, and the Czech Republic have different trends. The EYWC for Portugal fluctuated for approximately 10 years between the 1940s and 1950s birth cohorts. However, by the 1960 birth cohort, Portugal's EYWC increased and it is currently estimated to be at 11.6 years for the latest observed birth cohort. The Czech Republic, on the other hand, is different, as its EYWC does not have an increasing or decreasing trend. It has plateaued at 10 years for all observable birth cohorts from 1935 to 1965. Interestingly, the EYWC trend for Sweden also plateaued in recent cohorts. It initially increased from the 1955 birth cohort (14.4 years) but started to plateau by the 1960 birth cohort at 16 years.

In the latest birth cohorts that we can observe, Canada, Japan, and the Netherlands had approximately 17.5 years of EYWC, while Norway, Sweden, and the USA had approximately 
15 years. Following these countries, Portugal had 11.5 years, and the Czech Republic had fewer than 10 years. Small values for EYWC suggest that women gave birth to their first child at an early age. The latest cohort observed in Canada, Japan, and the Netherlands spent half of their reproduction periods without any child (the expected age at first birth is $15+17.5=32.5$ ). In other words, they only have 17.5 years left in their reproductive periods on average for any subsequent child.

The main objective of this study is to investigate whether the changes in EYWC, as seen in Fig Q2, are due to remaining childless, postponing childbirth, or the expansion effect. We decompose EYWC from 1940, and the results are presented in Fig 3 .

\section{Decomposition of EYWC}

For Canada, the USA, the Netherlands, Sweden and Norway, the location parameter (the timing of first childbirth) was the most influential factor in the changes in EYWC after 1950. Table $\mathbb{U}$ shows that $74 \%$ of the increase in the EYWC in Canada from 1955 to 1960 was due to the increase in the average age at first birth. Similar results can be observed for the USA; $68 \%$ of the increase in EYWC from 1958 to 1963 can be attributed to the increase in the average age at first birth. Likewise, the increase in the average age at first birth was responsible for 81\% of the increase in the EYWC of Norway from 1957 to 1962. The Netherlands and Sweden also exhibited very similar results. This suggests that more people of the current birth cohorts in these countries have postponed childbirth rather than remaining childless. The changes in the scale parameter or the proportion of women having children plays a less influential role in the current increase in the EYWC of these countries.

In addition, the Netherlands (1955 - 1960) and Sweden (1960 - 1965) show a negative value for the scale parameter in the most recent birth cohort, which implies that the proportion of women having a first child increased in those periods. The negative value of the scale factor in Sweden is coherent to the current decrease in the proportion of childless women (Persson 2010; Miettinen et al, 2015). The higher educational category has a more distinct decreasing 


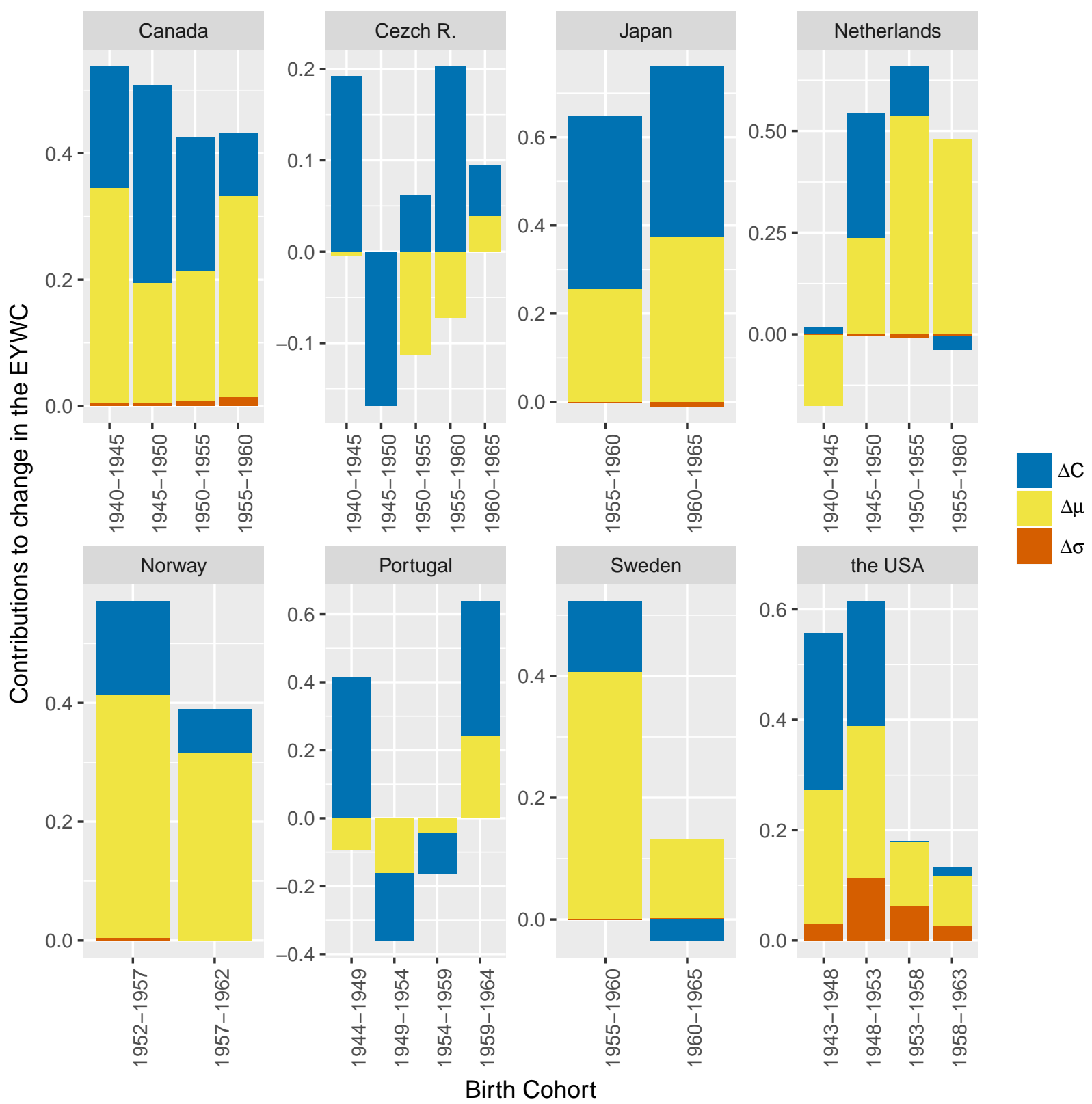

Figure 3: Decomposition of the change over time in females' expected years without children in eight countries

Source: Authors' calculations. 
trend (Persson 2010). Therefore, it might be that this negative value is mainly driven by a higher educational group.

Japan and Portugal, on the other hand, show different trends from the other countries. Either the scale parameter or the proportion of women having a child is the most influential factor for the changes in their EYWC after 1955 and 1959, respectively. For instance, Table 1 shows that $62 \%$ of the change in the EYWC of Portugal from 1959 to 1964 can be attributed to the scale parameter, which means that remaining childless was the main occurrence. Likewise, in Japan, the increase in EYWC was mainly due to the changes in scale parameter, even though the location parameter shared only approximately half as much impact on the latest change. This result indicates that more women in these countries remained childless rather than postponed their first birth to a later age. Regarding Japan, the strong linkage between marriage and childbearing may be a key to understanding the large impact of the scale factor. As the nonmarital birth rate is still at a low level, i.e., $2.29 \%$ in 2015 (National Institute of Population and Social Security Research 2017), most births occur in marital unions. Hence, the large influence of the scale factor for Japan may present an increase in the never-married population in Japan. Indeed, the never-married population at age 50 increased between 1980 and 2015 from $2.6 \%$ to $23.4 \%$ for males and from $4.5 \%$ to $14.1 \%$ for females (National Institute of Population and Social Security Research 2017). Never-married people are almost equal to childless people in Japan, which is why the scale factor in Japan is so influential compared to the other countries' trends. The interpretation of the Czech Republic is difficult because the trend of its EYWC fluctuated.

For all countries, changes in the variance parameter were observed not to be influential in the changes of EYWC except the USA. This result strongly indicates that changes in EYWC are mainly due to two factors, remaining childless and postponing childbirth. 
Table 1: Contribution of three parameters to decomposition of females' expected years without children $\left({ }_{35} \dot{e}_{15}(t)\right)$ in selected eight countries

\begin{tabular}{|c|c|c|c|c|c|c|}
\hline Country & Birth cohort & ${ }_{35} \dot{e}_{15}(t)$ & Scale & Location & Variance & Sum of all components \\
\hline \multirow[t]{4}{*}{ Canada } & $1940-1945$ & 0.2685 & $\begin{array}{l}0.0957 \\
(35.66)\end{array}$ & $\begin{array}{l}0.1698 \\
(63.26)\end{array}$ & $\begin{array}{c}0.0029 \\
(1.08)\end{array}$ & 0.2684 \\
\hline & $1945-1950$ & 0.2535 & $\begin{array}{l}0.1558 \\
(61.46)\end{array}$ & $\begin{array}{l}0.0951 \\
(37.51)\end{array}$ & $\begin{array}{c}0.0026 \\
(1.03)\end{array}$ & 0.2535 \\
\hline & $1950-1955$ & 0.2129 & $\begin{array}{l}0.1059 \\
(49.74)\end{array}$ & $\begin{array}{l}0.1027 \\
(48.24)\end{array}$ & $\begin{array}{c}0.0043 \\
(2.02)\end{array}$ & 0.2129 \\
\hline & $1955-1960$ & 0.2164 & $\begin{array}{l}0.0497 \\
(22.97)\end{array}$ & $\begin{array}{l}0.1597 \\
(73.80)\end{array}$ & $\begin{array}{l}0.0070 \\
(3.23)\end{array}$ & 0.2164 \\
\hline \multirow[t]{5}{*}{ Czech Republic } & $1940-1945$ & 0.0943 & 0.0963 & -0.0020 & 0.0000 & 0.0943 \\
\hline & $1945-1950$ & -0.0845 & -0.0844 & -0.0001 & 0.0000 & 0.0845 \\
\hline & $1950-1955$ & -0.0253 & 0.0311 & -0.0565 & 0.0000 & -0.0254 \\
\hline & $1955-1960$ & 0.0651 & 0.1012 & -0.0361 & 0.0000 & 0.0651 \\
\hline & $1960-1965$ & 0.0473 & $\begin{array}{l}0.0278 \\
(58.77)\end{array}$ & $\begin{array}{l}0.0195 \\
(41.23)\end{array}$ & $\begin{array}{c}0.0000 \\
(0.00)\end{array}$ & 0.0473 \\
\hline \multirow[t]{2}{*}{ Japan } & $1955-1960$ & 0.3232 & 0.1968 & 0.1276 & -0.0011 & 0.3232 \\
\hline & $1960-1965$ & 0.3749 & 0.1923 & 0.1875 & -0.0048 & 0.3750 \\
\hline \multirow[t]{4}{*}{ the Netherlands } & $1940-1945$ & -0.0789 & 0.0094 & -0.0883 & 0.0000 & -0.0789 \\
\hline & $1945-1950$ & 0.2709 & 0.1536 & 0.1186 & -0.0013 & 0.2709 \\
\hline & $1950-1955$ & 0.3247 & 0.0594 & 0.2695 & -0.0041 & 0.3249 \\
\hline & $1955-1960$ & 0.2205 & -0.0158 & 0.2395 & -0.0031 & 0.2206 \\
\hline \multirow[t]{2}{*}{ Norway } & $1952-1957$ & 0.2856 & $\begin{array}{l}0.0790 \\
(27.66)\end{array}$ & $\begin{array}{l}0.2045 \\
(71.60)\end{array}$ & $\begin{array}{c}0.0021 \\
(0.74)\end{array}$ & 0.2856 \\
\hline & $1957-1962$ & 0.1951 & $\begin{array}{l}0.0368 \\
(18.85)\end{array}$ & $\begin{array}{l}0.1582 \\
(81.05)\end{array}$ & $\begin{array}{l}0.0002 \\
(0.10)\end{array}$ & 0.1952 \\
\hline \multirow[t]{4}{*}{ Portugal } & $1944-1949$ & 0.1611 & 0.2075 & -0.0462 & 0.0003 & 0.1615 \\
\hline & $1949-1954$ & -0.1796 & -0.0996 & -0.0803 & 0.0003 & -0.1796 \\
\hline & $1954-1959$ & -0.0823 & -0.0606 & -0.0216 & 0.0001 & -0.0824 \\
\hline & $1959-1964$ & 0.3192 & $\begin{array}{l}0.1980 \\
(62.03)\end{array}$ & $\begin{array}{l}0.1205 \\
(37.75)\end{array}$ & $\begin{array}{c}0.0007 \\
(0.22)\end{array}$ & 0.3192 \\
\hline \multirow[t]{2}{*}{ Sweden } & $1955-1960$ & 0.2611 & 0.0578 & 0.2037 & -0.0002 & 0.2613 \\
\hline & $1960-1965$ & 0.0485 & -0.0173 & 0.0643 & 0.0015 & 0.0485 \\
\hline \multirow[t]{4}{*}{ the USA } & $1943-1948$ & 0.2785 & $\begin{array}{l}0.1422 \\
(51.08)\end{array}$ & $\begin{array}{l}0.1202 \\
(43.18)\end{array}$ & $\begin{array}{c}0.0160 \\
(5.75)\end{array}$ & 0.2784 \\
\hline & $1948-1953$ & 0.3082 & $\begin{array}{l}0.1131 \\
(36.78)\end{array}$ & $\begin{array}{l}0.1376 \\
(44.75)\end{array}$ & $\begin{array}{l}0.0568 \\
(18.47)\end{array}$ & 0.3075 \\
\hline & $1953-1958$ & 0.0902 & $\begin{array}{l}0.0007 \\
(0.78)\end{array}$ & $\begin{array}{l}0.0578 \\
(64.08)\end{array}$ & $\begin{array}{l}0.0318 \\
(35.25)\end{array}$ & 0.0902 \\
\hline & $1958-1963$ & 0.0667 & $\begin{array}{l}0.0077 \\
(11.54)\end{array}$ & $\begin{array}{l}0.0455 \\
(68.22)\end{array}$ & $\begin{array}{l}0.0136 \\
(20.39)\end{array}$ & 0.0667 \\
\hline
\end{tabular}

Note: Percentages are presented under the each value in parentheses and are calculated only when all terms go in the same direction. The sum of all components (Scale, Location, and Variance) varies slightly from the difference in the expected years without children $\left.{ }_{35} \dot{e}_{15}(t)\right)$, due to rounding the numbers to the third decimal point in the table.

Source: Authors' calculations. 


\section{Conclusion}

Childlessness has caught the attention of demographers in recent decades. The rise of childlessness in developed countries may show an emerging new way of life, and it has several influences on the female life course (Kendig et al. 2007; Albertini and Kohli 200); Budig et al. 2012; Huijts et al. 2013). The increase in childless women has been observed throughout Europe (Beaujouan et al. 2015; Miettinen et al. 2015; Kreyenfeld and Konietzka 2017), North America (the USA: Frejka (2017), Canada: Ravanera and Beaujot (2014)) and Japan (Raymo et al. 2015). Accompanied by this trend, the mean age at first childbirth has also increased (Beaujouan et al. 2015; Sobotka 2017). This increase has raised an important question about which phenomena are the main reasons for the change in first birth behaviors. This study addresses this question by investigating whether the changes in the expected years without children (EYWC) are due to people remaining childless or just postponing the first childbirth or due to the expansion of variance of the mean age at first birth.

This study used cohort data for eight developed countries from the Human Fertility Database (HFD) and followed the decomposition method developed by Mogi and CanudasRomo (2018) to quantify the effect of the aforementioned phenomena on EYWC. Analysis of the trends shows that the EYWC of Canada, the USA, the Netherlands, Japan and Norway steadily increased through cohorts. EYWC in Sweden increased until the 1960 birth cohort and then remained at the same level. Portugal increased from the late 1950s cohort after fluctuating. EYWC in the Czech Republic bore no strong trends throughout cohorts that can be observed. The decomposition results strongly indicate that changes in EYWC are mainly due to two factors, remaining childless and the postponement of childbirth. Findings of the decomposition analysis show that more people postpone first childbirth to a late age rather than remaining childless in Canada, the USA, the Netherlands, Sweden and Norway. The EYWC for these countries has an increasing trend mainly because their female populations have delayed childbirth. This could be a result of improvements in female education, labor force participation and better access to effective contraceptive methods. On the other hand, 
more women remain childless rather than postpone childbirth in Japan and Portugal. The variance factor did not have an important impact on the changes in EYWC for all periods and countries analyzed except the USA.

Interpretation of the results should be done with caution. First, this study cannot distinguish between voluntary and involuntary childlessness. Hence, the scale factor measured by the proportion of women who have children does not present those who are voluntarily childless. In fact, it also contains involuntary childlessness, since women have a biological limit to giving birth, postponing childbirth until the end of reproductive age may ultimately lead to childlessness (Schmidt et al. 2012). Second, the study is limited in terms of its coverage of countries due to the inclusion criteria imposed on the data that came from HFD.

The contributions of our study are threefold. First, we performed a statistical examination of the CM model to estimate the age patterns at first birth using the KolmogorovSmirnov test. The CM model fits statistically well all countries and cohorts in this study. Thus, although the CM model was originally developed for the estimation of first marriage behavior, our study showed it fits well to the age patterns of first birth. Second, we suggested a new index: expected years without children (EYWC) to measure the first birth trend using the classical demographic method. This is an alternative way of describing childless/first birth trend with one simple index. The CM model and EYWC have the potential to develop fertility research. Third, we quantify the impact of remaining childless and postponing childbirth and show that postponing first birth is the main factor in Canada, the USA, the Netherlands, Sweden and Norway and childless is the main factor in Japan and Portugal. Finally, for future research, it is worthwhile to apply this decomposition method to subpopulations, such as educational groups. It is well known that the timing of first birth differs by educational gradients. Although the proportion of childlessness is only marginally different from the educational level in Europe (Beaujouan et al. 2015), each educational group has a distinct trend of EYWC and effects of the three factors on it. This idea is applicable to union status (e.g., single, cohabitation, married) and race/ethnicity as well. 


\section{Appendices}

\section{Appendix A The statistical test of the CM model}

We conducted a statistical examination of the CM model using the Kolmogorov-Smirnov test (KS test). The KS test is a nonparametric test to check the goodness-of-fit of the observed distribution and the estimated one by the CM model. The test statistic D of the KS test quantifies the supremum distance between the empirical distribution function of the data and the cumulative distribution function of the CM distribution. The null distribution of this statistic is calculated under the null hypothesis that the data follow the CM distribution. Thus, a p-value greater than $\alpha=0.05$ indicates that the data and the CM model have a good fit. As Table 2 shows, the CM model estimated the observed data statistically well for all countries and birth cohorts.

Table 2: Goodness-of-fit of the CM model using Kolmogorov-Smirnov test

\begin{tabular}{cccccccc}
\hline Country & Birth cohort & $\mathrm{D}$ & P-value & Country & Birth cohort & D & P-value \\
\hline Canada & 1940 & 0.1429 & 0.8745 & Norway & 1952 & 0.1429 & 0.8674 \\
& 1945 & 0.1714 & 0.6902 & & 1957 & 0.2000 & 0.4858 \\
& 1950 & 0.1714 & 0.6902 & & 1962 & 0.1714 & 0.6902 \\
Czech Republic & 1955 & 0.1714 & 0.6902 & Portugal & 1944 & 0.2000 & 0.4916 \\
& 1960 & 0.1714 & 0.6902 & & 1949 & 0.1429 & 0.8674 \\
& 1940 & 0.1143 & 0.9794 & & 1954 & 0.1143 & 0.9763 \\
& 1945 & 0.1429 & 0.8674 & & 1959 & 0.1143 & 0.9794 \\
Japan & 1950 & 0.1143 & 0.9763 & & 1964 & 0.1714 & 0.6902 \\
& 1955 & 0.0857 & 0.9995 & Sweden & 1955 & 0.1714 & 0.6902 \\
& 1960 & 0.1143 & 0.9763 & & 1960 & 0.1714 & 0.6902 \\
the Netherlands & 1965 & 0.1143 & 0.9763 & & 1965 & 0.1429 & 0.8745 \\
& 1955 & 0.1143 & 0.9794 & the USA & 1943 & 0.1143 & 0.9794 \\
& 1960 & 0.1143 & 0.9794 & & 1948 & 0.1429 & 0.8745 \\
& 1965 & 0.1714 & 0.6902 & & 1953 & 0.1714 & 0.6902 \\
& 1940 & 0.1714 & 0.6826 & & 1958 & 0.1714 & 0.6902 \\
& 1945 & 0.1143 & 0.9763 & & 1963 & 0.1714 & 0.6902 \\
& 1950 & 0.1429 & 0.8745 & & & & \\
\hline
\end{tabular}

Source: Authors' calculations. 


\section{Appendix B Calculation Process: Expected years with- out children}

The life expectancy from age 0 to age $X$ is shown as

$$
{ }_{X} e_{0}(t)=\int_{0}^{X} l_{x, t} d x
$$

We call the life expectancy between age 15 and age 50 the expected years without children (denoted $\left.{ }_{35} e_{15}(t)\right)$. It is formulated as follows:

$$
\begin{aligned}
{ }_{35} e_{15}(t) & =\int_{15}^{50} l_{x, t} d x \\
& =35-\int_{15}^{50} F_{x, t} d x,
\end{aligned}
$$

where $l_{x}$ is the probability of remaining childless and $F_{x}$ is its cumulative probability function. The detailed calculation procedure can be found in Mogi and Canudas-Romo (2018).

\section{Appendix C The decomposition to discrete data}

Three parameters of $f_{x}$ are estimated using the maximum likelihood estimation method as suggested by Rodríguez and 'Trussell (1980).

$$
\operatorname{lnLH}=\sum_{15}^{49}\left(\text { With }_{x} \log \left[F_{(x+0.5)}\right]+\text { Without }_{x} \log \left[1-F_{(x+0.5)}\right]\right)
$$

where $\mathrm{With}_{x}$ is the female population with children at age $x$, Without $x$ is the female population without children at age $x$, and $F_{x}$ is the cumulative probability function at age $x$.

Vaupel and Canudas-Romo (2003) and Bergeron-Boucher et al. (2015) applied the continuous decomposition equation to discrete time data and we followed their method. To 
estimate each function applying our decomposition method to discrete time data, we use the midpoint over a time interval (Preston et al. 2001). For the functions except EYWC, an exponential change assumption is used.

$$
v_{x, t+\frac{h}{2}}=v_{x, t}\left(\frac{v_{x, t+h}}{v_{x, t}}\right)^{0.5}
$$

The derivative of the function $v_{x, t+\frac{h}{2}}$ was estimated by

$$
\dot{v}_{x, t+\frac{h}{2}}=v_{x, t+\frac{h}{2}}\left(\frac{\log \left[\frac{v_{x, t+h}}{v_{x, t}}\right]}{h}\right) .
$$

The midpoint of EYWC is assumed to be a linear change in the interval, which is

$$
v_{x, t+\frac{h}{2}}=\frac{v_{x, t+h}+v_{x, t}}{2},
$$

and

$$
\dot{v}_{x, t+\frac{h}{2}}=\frac{v_{x, t+h}-v_{x, t}}{h}
$$




\section{References}

Albertini, M. and Kohli, M. (2009). What childless older people give: is the generational link broken?. Ageing and Society 29(08), 1261-1274.

Beaujouan, E., Brzozowska, Z., and Zeman, K. (2015). Childlessness trends in twentiethcentury Europe: limited link to growing educational attainment. VID Working paper: Vienna Institute of Demography 6.

Bergeron-Boucher, M.-P., Ebeling, M., and Canudas-Romo, V. (2015). Decomposing changes in life expectancy: Compression versus shifting mortality. Demographic Research 33(14), $391-424$.

Bloom, D. E. (1982a). Age patterns of women at first birth. Genus 38(3-4), 101-128.

Bloom, D. E. (1982b). What's happening to the age at first birth in the United States? A study of recent cohorts. Demography 19(3), 351-370.

Bloom, D. E. and Trussell, J. (1984). What are the determinants of delayed childbearing and permanent childlessness in the United States?. Demography 21(4), 591-611.

Budig, M. J., Misra, J., and Boeckmann, I. (2012). The motherhood penalty in cross-national perspective: The importance of workfamily policies and cultural attitudes. Social Politics: International Studies in Gender, State $\&$ Society 19(2), 163-193.

Coale, A. J. and Trussell, T. J. (1978). Technical note: Finding the two parameters that specify a model schedule of marital fertility. Population Index 44(2), 203-213.

department of health, U. and human services (2018). National Center for Health Statistics. [electric resource]. https://catalog.data.gov/dataset/nonmarital-birth-rates-by-age-groupfor-all-women-age-15-44-united-states-1980-2013 (accessed on 23rd of November, 2018). 
Eurostat (2018). Eurostat Database. [electric resource]. https://ec.europa.eu/eurostat/web/population-demography-migrationprojections/births-fertility-data/main-tables (accessed on 23rd of November, 2018).

Frejka, T. (2017). Childlessness in the United States. In: Kreyenfeld, M. and Konietzka, D. (Eds.). Childlessness in Europe: Contexts, Causes, and Consequences. Demographic Research Monographs. Cham: Springer International Publishing: 159-179.

Henz, U. and Huinink, J. (1999). Problems concerning the parametric analysis of the age at first birth. Mathematical Population Studies 7(2), 131-145.

Huijts, T., Kraaykamp, G., and Subramanian, S. V. (2013). Childlessness and psychological well-being in context: A multilevel study on 24 European Countries. European Sociological Review 29(1), 32-47.

Kendig, H., Dykstra, P. A., van Gaalen, R. I., and Melkas, T. (2007). Health of aging parents and childless individuals. Journal of Family Issues 28(11), 1457-1486.

Kostaki, A. and Paraskevi, P. (2007). Modeling fertility in modern populations. Demographic Research 16, 141-194.

Kreyenfeld, M. and Konietzka, D. (Eds.) (2017). Childlessness in Europe: Contexts, Causes, and Consequences. Demographic Research Monographs. Cham: Springer International Publishing.

Miettinen, A., Rotkirch, A., Szalma, I., Donno, A., and Tanturri, M.-L. (2015). Increasing childlessness in Europe: Time trends and country differences. Families And Societies Working Paper Series 33, 1-66.

Mogi, R. and Canudas-Romo, V. (2018). Expected years ever married. Demographic Research 38(47), 1423-1456. 
National Institute of Population and Social Security Research (2017). Recent demographic statistics. Tokyo [in Japanese]. National Institute of Population and Social Security Research.

Persson, L. (2010). Trend reversal in childlessness in Sweden. In: Work session on demographic projections. Methodologies and working papers. Publications Office of the European Union. Luxembourg. : 129-135.

Preston, S., Heuveline, P., and Guillot, M. (2001). Demography: Measuring and modeling population processes. Oxford: Blackwell.

Rao, K. V. (1987). Demographic models of age at first marriage and first birth: An application to Canadian data. Digitized theses.

Ravanera, Z. and Beaujot, R. (2014). Childlessness of men in Canada: Result of a waiting game in a changing family context. Canadian Studies in Population 41(1-2), 38-60.

Raymo, J. M., Park, H., Xie, Y., and Yeung, W.-j. J. (2015). Marriage and family in East Asia: Continuity and change. Annual Review of Sociology 41(1), 471-492.

Rodríguez, G. and Trussell, J. (1980). Maximum likelihood estimation of the parameters of Coale's model nuptiality schedule from survey data. Voorburg: International Statistical Institute (World Fertility Survey Technical Bulletins, 7).

Schmidt, L., Sobotka, T., Bentzen, J. G., and Andersen, A. N. (2012). Demographic and medical consequences of the postponement of parenthood. Human Reproduction Update 18(1), 29-43.

Sobotka, T. (2017). Childlessness in Europe: Reconstructing long-term trends among women born in 1900-1972. In: Kreyenfeld, M. and Konietzka, D. (Eds.). Childlessness in Europe: Contexts, Causes, and Consequences. Demographic Research Monographs. Cham: Springer International Publishing: 17-53. 
Trussell, J. and Bloom, D. E. (1983). Estimating the co-variates of age at marriage and first birth. Population Studies 37(3), 403-416.

Vaupel, J. W. and Canudas-Romo, V. (2003). Decomposing change in life expectancy: A bouquet of formulas in honor of Nathan Keyfitz's 90th birthday. Demography 40(2), 201216.

Zeman, K., Beaujouan, É., Brzozowska, Z., and Sobotka, T. (2017). Cohort fertility decline in low fertility countries: Decomposition using parity progression ratios. VID Working paper: Vienna Institute of Demography and Human Fertility Database Research Report 3. 